\title{
Characterisation of the mechanical behaviour of the bell tower of the cathedral of San Miniato (Pisa)
}

\author{
R. Barsotti, S. Bennati, L. Nardini \& W. Salvatore \\ Department of Structural Engineering, University of Pisa, Italy
}

\begin{abstract}
This paper reports the results of a wide-ranging study performed on the Tower of Matilde, the masonry bell tower of the Cathedral of San Miniato (Pisa, Italy). The structure, dating back to the XII century, has been subjected to various modifications over the centuries: from military fortification, to the bell tower incorporated into the church. The research followed a multidisciplinary approach to studying the tower, combining static and dynamic experimental analyses, structural FE modelling and updating through a suitable methodology seldom used in practice on masonry constructions. The aim was to achieve accurate characterization of the overall behaviour of whole masonry construction and the mechanical properties of its constituent materials.
\end{abstract}

Keywords: masonry structures, static tests, system identification, model updating.

\section{Introduction}

Nowadays, a reliable and effective estimation of the mechanical behaviour and load-bearing capacity of historical masonry structures is still an open issue. Despite the importance of such problems and the large number of relevant research studies (see for example [1-4]), no commonly shared methodology exists for characterising the mechanical properties of historical masonries. The various current methods, all based on either non-destructive or semi-destructive techniques, can be categorised as static tests (flat-jack test, diagonal compression test), or dynamic tests (sonic test, vibration measurements [3, 4]). Static tests allow for determining some mechanical parameters in the neighbourhood of the measurement point. Such tests, however, suffer from considerable scattering of the measured values due to the lack of homogeneity typical of historical masonry 
constructions, which in many cases have been built in various stages over long periods of time. Dynamic tests, on the other hand, enable direct determination of quantities defining the global dynamic response of the entire structure (eigenfrequencies, damping ratios and mode shapes): application of suitable inverse methods to such results provides indirect estimates of the mean values of some mechanical properties (e.g. elastic modulus, mass density). However, the resulting estimates depend heavily on the chosen initial values and the mechanical model used. Hence, in recent years a number of improved techniques have been proposed with the aim of providing a better estimation of the mechanical properties and load-bearing capacity of masonry structures. Nevertheless, to date, the strategy of combining the two types of methods - static and dynamic testing - to characterise the mechanical properties of masonry has only rarely been applied effectively [5]. Therefore, their possible integration seems to be of a certain interest.

\section{The tower of Matilde}

The Tower of Matilde is the masonry bell tower of the Cathedral of Santa Maria e San Genesio in San Miniato (Pisa, Italy). The structure, about 35 meters in height with a rectangular cross section 10 by 7 meters (Figure 1), dates back to the mid- $12^{\text {th }}$ century as a military fortification incorporated into the old city walls, today completely destroyed $[6,7]$.

The original structure of the tower was quite different from its current one; it probably had a crenelated crown and certainly had three tiers of semicircular arches of varying heights, today partially closed.

In the $13^{\text {th }}$ century the Tower of Matilde was incorporated, abutting one of the gateways, into the new fortified city walls built by order of Emperor Frederick II of Swabia. The ogival arched barbicans, the trim of the semicircular windows and the square aedicule at the corners of the roof were added during this period.

The most significant structural modifications were carried out towards the end of the $15^{\text {th }}$ century, when the Cathedral was enlarged to include the tower above the apse of the main nave. These restructuring works involved demolition of the tower wall, on the church side, up to the height of the nave itself.

In 1438 a balance-wheel movement clock was set in the tower, and in 1497 the first bell was installed, while five further ones were added some years later.

In 1623 the sacristies were built closing the tower off laterally: this probably involved demolition of the southern and eastern side scarps.

In the $18^{\text {th }}$ and $19^{\text {th }}$ centuries restoration works were carried out on the church, during which other structures were built abutting the base of the Tower.

The general plan and the main views of the Tower and church are shown in Figure 1, while in Figure 2 illustrates the vertical and horizontal cross sections.

The Tower is now divided vertically into four levels: a) the church apse, b) the middle floor, c) the belfry and d) the upper floor, closed by the terrace roof.

The cross-sectional dimensions vary from about $12.5 \times 8.2 \mathrm{~m}$ in its lower part to $10.3 \mathrm{~m} \times 7.3 \mathrm{~m}$ in the upper portions up to the crown, which is $11 \mathrm{~m} \times 7.8 \mathrm{~m}$. 
It is likely that when the function of the tower was changed from watchtower to bell tower and it was incorporated into the Cathedral, the $30 \mathrm{~cm}$-thick external walls were buttressed by another, considerably thicker wall (about $100 \mathrm{~cm}$ ). This reinforcing wall is however arranged differently on the various sides and along the height of the tower. Recent endoscopies, performed at the middle floor level (Figure 3), have shown that the tower walls are stratified with a conglomerate layer interposed between two masonry ones.
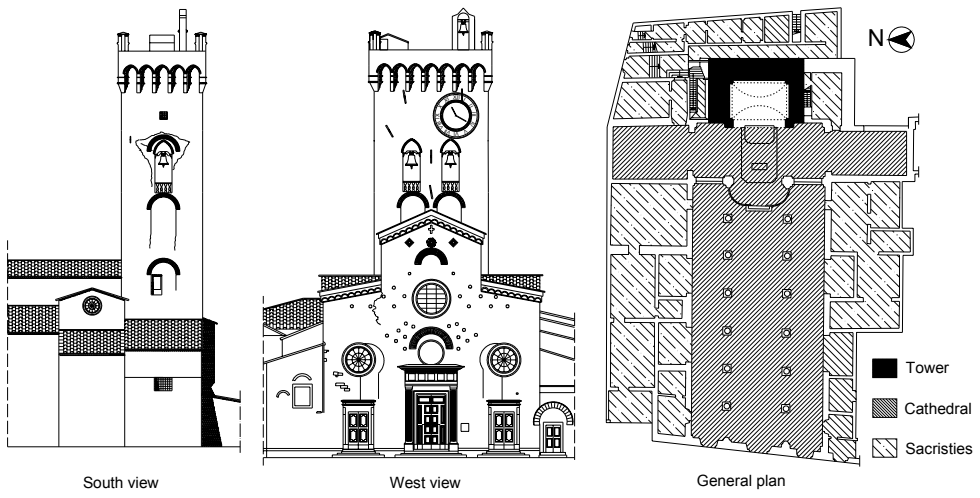

Figure 1: The Tower of Matilde.
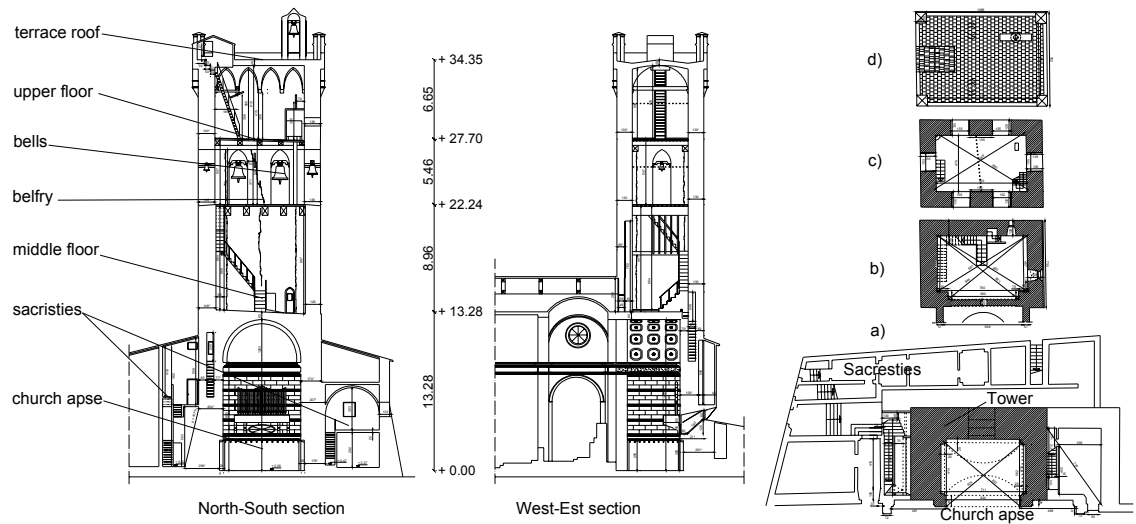

Figure 2: Vertical and horizontal sections.

The Tower of Matilde shows a wide-spread cracking pattern visible along the walls at different heights, almost surely due to the dynamic actions transmitted by the bells. Furthermore, numerous stiffening chains have been placed both in the belfry and at the upper floor level, some limited to a single masonry wall, others linking opposite walls. 


\section{Experimental programme}

In previous experimental and analytical studies performed on the tower [8,9], rather high values of acceleration (about $0.20 \mathrm{~m} / \mathrm{s}^{2}$ ) were recorded when the tower was subjected to the dynamic actions produced by the motion of the bells. The accelerations, due to quasi-resonance phenomena, were reached several times a day and have probably caused a clearly visible, alarming cracking pattern, particularly in correspondence to the belfry and the connection with the church structure (Figure 4). Such reasons, together with the medium-high seismicity of the San Miniato area, have aroused serious concerns about its current and future integrity $[10,11]$. Thus, the structural behaviour of the tower has been analyzed in depth in order to assess its safety and integrity and compile an information base for possible future refurbishment or restoration works. In particular, the experimental programme consisted of a series of static single and double flat jack tests and dynamic tests measuring the accelerations of the tower under different types of applied forces.

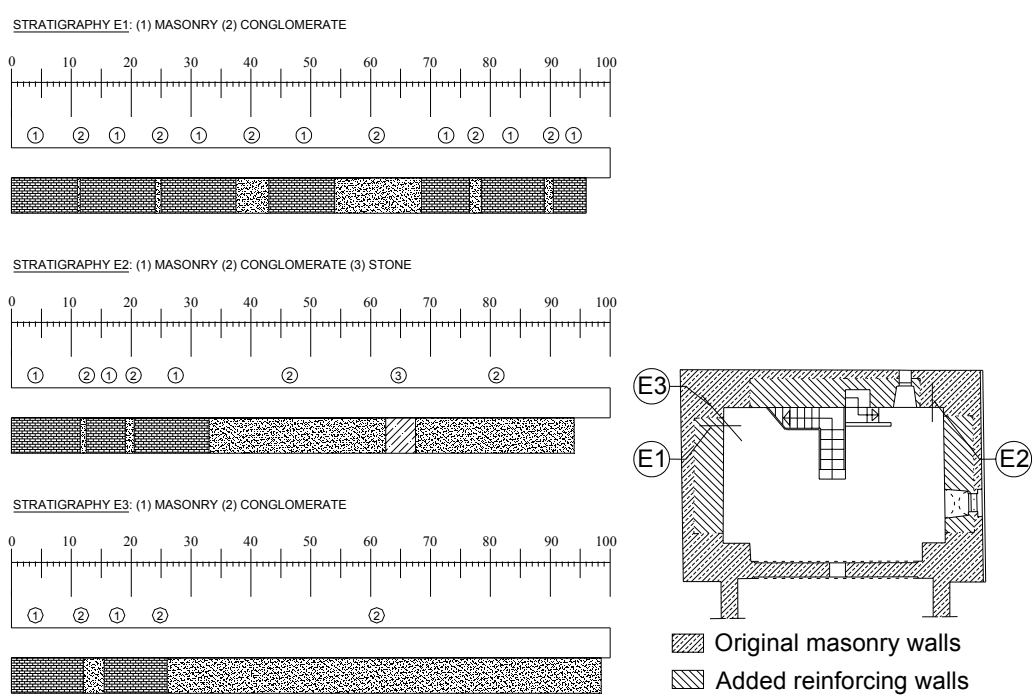

Figure 3: Stratigraphies of the masonry walls.

\subsection{Static tests}

The mechanical properties of the masonry constituting the vertical walls were investigated via single and double flat jack tests performed at four different levels along the tower's height (see Table 1). Each test was executed over a portion of brick masonry in good condition and showing no visible cracks. 


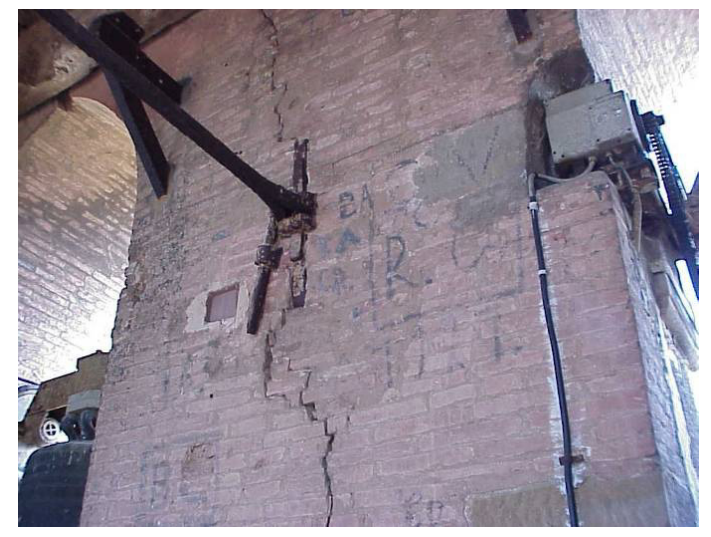

Figure 4: Cracking pattern and chains at the belfry level.

Table 1: $\quad$ Flat jack tests performed.

\begin{tabular}{lcc}
\hline Location & $\begin{array}{c}\text { Single flat } \\
\text { jack test }\end{array}$ & $\begin{array}{c}\text { Double flat } \\
\text { jack test }\end{array}$ \\
\hline Sacristies & S1 & D1 \\
Middle floor & S2 & D2 \\
Belfry & S3 & D3 \\
Upper floor & S4 & D4 \\
\hline
\end{tabular}

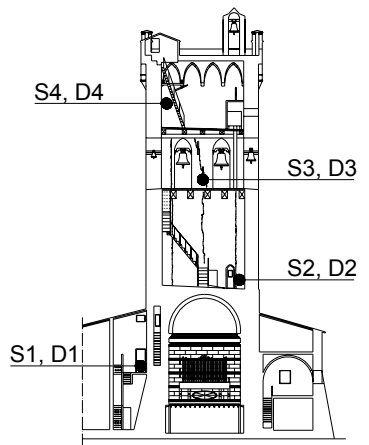

The results obtained from the single flat jack tests are summarized in Table 2, which reports the experimental values of the mean compressive vertical stresses $\sigma_{\mathrm{m}}$, as well as a rough estimation of the masonry secant modulus of elasticity based on the displacements measured by the transducers and the pressure in the flat-jack.

Flat jack tests obviously involved only the outer layer of the walls. Extending the results obtained to the inner layers is therefore not a straightforward matter, since the composition and texture of the masonry differ greatly from point to point (see Figure 3).

The large variations found in the values of the secant Young's modulus highlight the strong heterogeneity of the different masonries present in the bell tower, built up in several stages over a long period of time.

The values of compressive stress $\sigma_{\mathrm{m}}$ obtained by means of the single flat-jack tests turned out to be greater than the corresponding ones assessed by means of simple equilibrium considerations, assuming a uniform stress distribution within each cross-section of the tower. Such differences, however, are anything but 
surprising. First of all, the occurrence in the masonry of stress localisations as well as viscoelastic long-term stress redistribution phenomena should not be excluded. Moreover, the well-known conventional character of the stress values deduced via single flat-jack tests should also be kept in mind.

The four double flat jack tests, performed near the single ones, yielded the stress-strain diagrams showed in Figure 5. Wide variations in the mechanical response of the masonry at the different levels may be observed. The scattering of these results further confirms the great variability of the mechanical properties of the masonries.

From the double flat jack tests, two sets of values of Young's modulus of the brick masonry can be deduced: the tangent values $E_{\mathrm{m}, \mathrm{t}}$ and the secant values $E_{\mathrm{m}, \mathrm{s}}$. By using the experimental stress-strain diagram obtained from each test, the tangent value $E_{\mathrm{m}, \mathrm{t}}$ has been calculated by executing a linear regression of the experimental data recorded in the neighbourhood of the mean compressive stress level $\sigma_{\mathrm{m}}$ estimated in the wall (two examples are shown in Fig. 6). The secant value $E_{\mathrm{m}, \mathrm{s}}$ has been calculated as the slope of the straight line connecting the origin of the axes and the point at ordinate $\sigma_{\mathrm{m}}$ in the experimental diagram. The plots of both tangent and secant values of Young's modulus are shown in Fig. 7.

Table 2: $\quad$ Results of the single flat jack tests.

\begin{tabular}{ccc}
\hline Single flat jack test & $\begin{array}{c}\text { Compressive stress } \sigma_{m} \\
{[M P a]}\end{array}$ & $\begin{array}{c}\text { Secant Young's modulus } \\
{[\text { GPa] }}\end{array}$ \\
\hline S1 & 2.15 & 1.178 \\
S2 & 1.24 & 1.495 \\
S3 & 0.80 & 2.627 \\
S4 & 0.26 & 0.593 \\
\hline
\end{tabular}

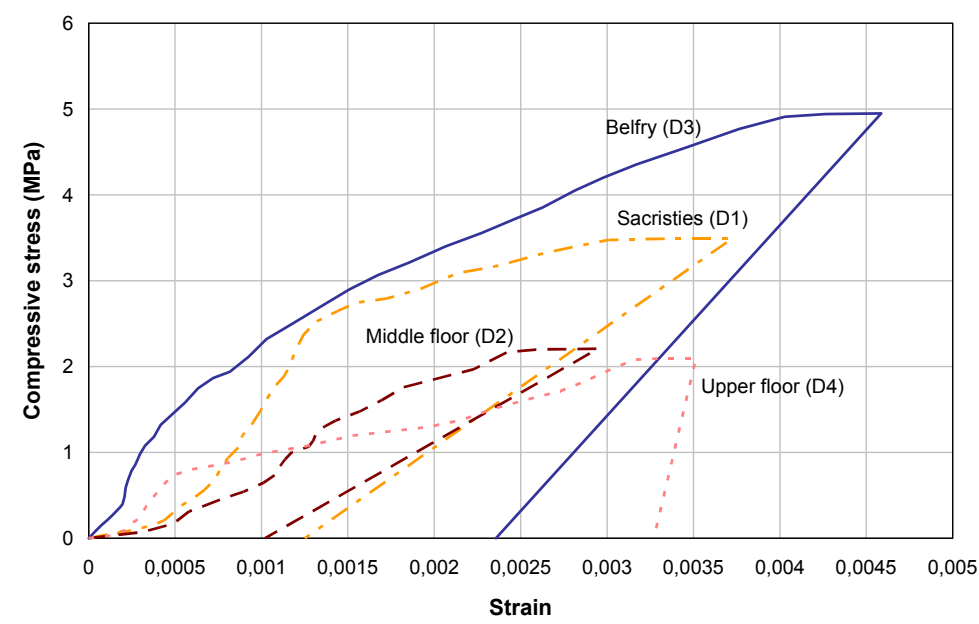

Figure 5: $\quad$ Stress-strain diagrams obtained from double flat jack tests. 
From the two diagrams, it can be seen that the values of the masonry's secant elastic modulus show quite similar trends and a rather good correlation (the correlation index $=0.872$ ). Moreover, the curve of the tangent elastic moduli turns out to be simply shifted towards higher values in comparison to the corresponding secant values, as is to be expected since the tangent values are not affected by the softer initial phase of the tests.
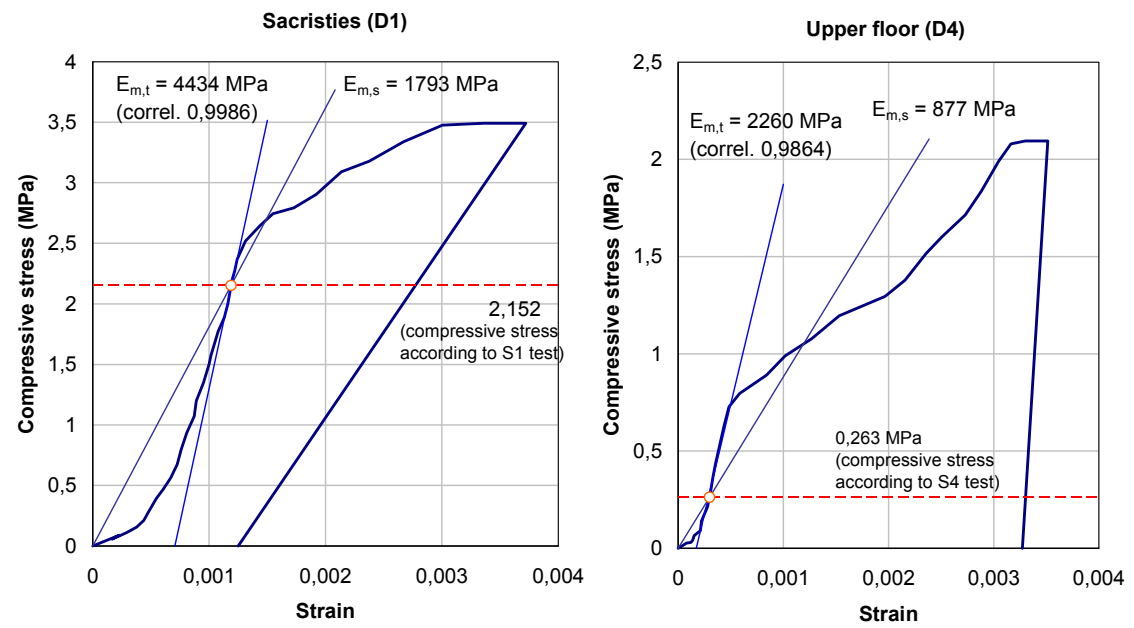

Figure 6: Tangent and secant elastic modulus (left: sacristies; right: upper floor).

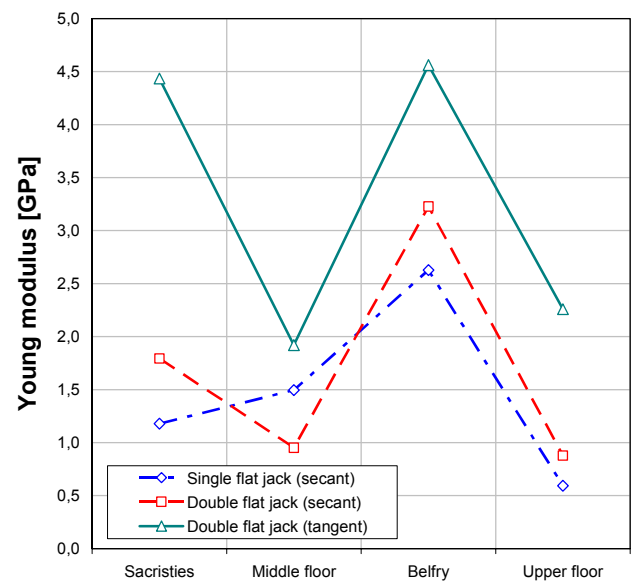

Figure 7: Tangent and secant values of the masonry Young's modulus. 


\subsection{Dynamic tests}

The structural behaviour of the Tower of Matilde was also investigated by means of suitably designed experimental dynamic analyses, measuring the response of the structure under applied dynamic forces.

The accelerometers were positioned in such as way as to capture the global dynamic behaviour of the structure, measuring both horizontal and vertical accelerations throughout the tower's height.

A total number of 21 accelerometers were placed at 5 levels along the tower's height; two additional ones were placed on the church walls in order to check the transmission of vibrations from the tower to the church structure (Figure 8).

The structure was subjected to different types of excitations: i) an impulsive force produced by the impact of a sledgehammer (shock test) applied at the top level of the structure in two orthogonal directions; ii) a harmonic force, generated by an electromagnetic shaker (stepped sine test) fixed on the terrace roof access. Both the input and output signals were processed via an amplifier and acquired choosing a sampling frequency of $800 \mathrm{~Hz}$. In addition, the structure was subjected to the dynamic actions produced by the swinging of the largest bell, fixed directly to the tower walls. This last type of excitation source was chosen for testing purposes because it is the most frequent action on the structure, repeated several times a day.
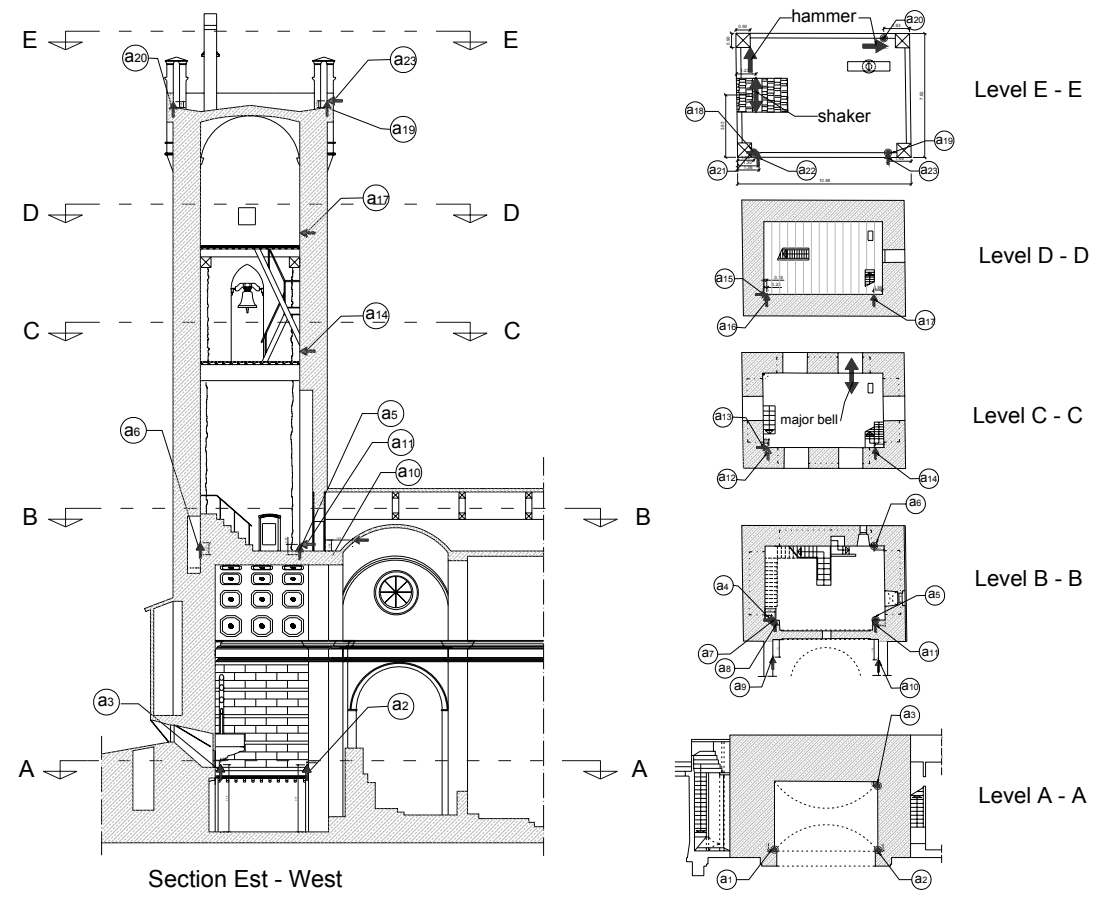

Figure 8: Location of the accelerometers. 


\subsection{System modal identification}

The recorded vibration data have been analyzed by means of two modal identification techniques: the Non-Linear Least Squares (NLLS) and the Stochastic Subspace Identification (SSI) [12].

Figure 9 illustrates the five mode shapes extracted via the two modal identification techniques. The corresponding eigenfrequencies $f$ and damping ratios $\xi$ are listed in Table 3: it is clear that the results of the two methods agree quite well with regard to frequency content and modal displacements, as evidenced by the Modal Assurance Criterion (MAC), but not nearly as well for damping. The extracted modes denote a complex three-dimensional behaviour of the tower: the first and second mode shapes respectively describe flexural deformation in the E-W and orthogonal, N-S direction, the third mode describes torsional deformation, while the fourth and fifth, combined bending and torsion.

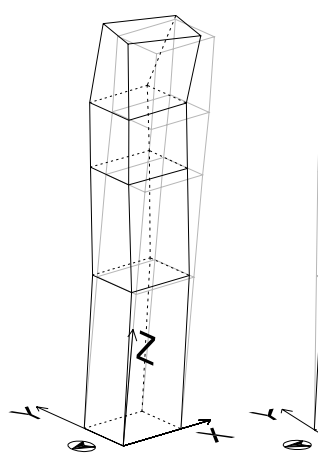

Mode $1 \quad$ Mode

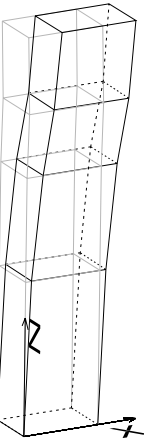

Mode 3

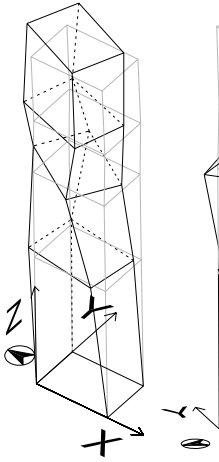

Mode 4

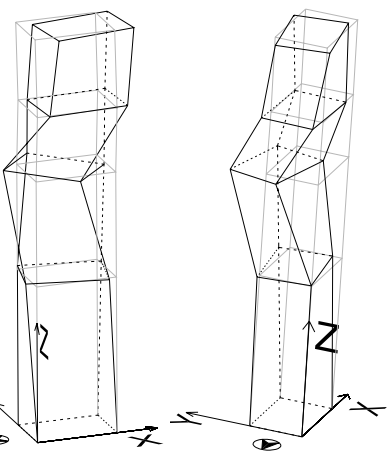

Mode 5

Figure 9: $\quad$ The five identified mode shapes.

Table 3: $\quad$ Comparison between identified modes.

\begin{tabular}{cccccc}
\hline & \multicolumn{2}{c}{ NLLS } & \multicolumn{2}{c}{ SSI } & MAC \\
\cline { 2 - 6 } & $f[\mathrm{~Hz}]$ & $\xi[\%]$ & $f[\mathrm{~Hz}]$ & $\xi[\%]$ & {$[\%]$} \\
\hline 1 & 1.28 & 1.22 & 1.28 & 1.75 & 95.16 \\
2 & 1.83 & 3.56 & 1.82 & 2.11 & 92.72 \\
3 & 3.00 & 1.17 & 3.03 & 1.23 & 94.41 \\
4 & 4.61 & 0.51 & 4.498 & 0.5 & 73.97 \\
5 & 6.33 & 0.34 & 6.187 & 0.21 & 93.54 \\
\hline
\end{tabular}

\subsection{FE modelling: development and updating}

Based on previous studies conducted on the structure $[8,9]$, a detailed linearelastic, three-dimensional FE model has been developed using the ADINA software (Figure 10). Such an FE model accurately reproduces all variations in 
wall thickness, irregularities of resistant sections, the most significant openings and the staircase running within the building's northern and eastern outer walls. In order to take into account the constraints exerted by the structures surrounding the tower, the load-bearing walls of the adjacent buildings (sacristies) were modelled as well. The connection with the church structure, formed by a spherical vault and two arches, has been modelled by 8 spring elements located at the top of the apse opening. Regarding the base constraints, the foundation was assumed to be perfectly bonded to a rigid soil.

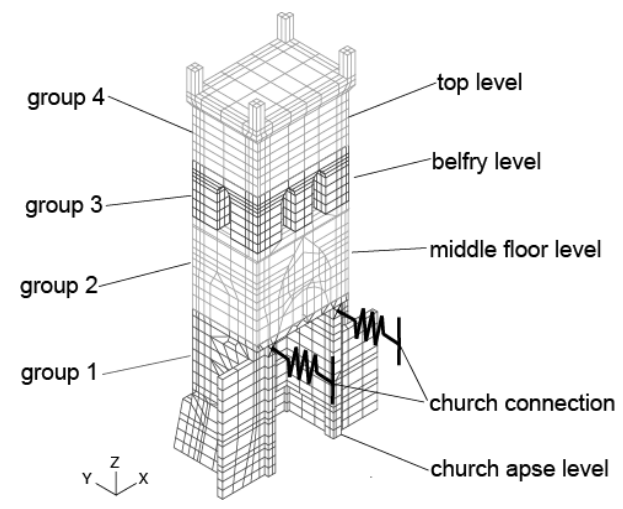

Figure 10: The FE model of the tower.

Table 4: $\quad$ Comparison between experimental and ADINA modes.

\begin{tabular}{ccccc}
\hline & $f_{\exp }[\mathrm{Hz}]$ & $f_{\text {ADINA }}[\mathrm{Hz}]$ & $\Delta \mathrm{f}[\%]$ & $\mathrm{MAC}[\%]$ \\
\hline 1 & 1.28 & 1.33 & -3.64 & 78.61 \\
2 & 1.82 & 1.96 & -7.50 & 96.39 \\
3 & 3.03 & 3.48 & -14.84 & 72.59 \\
4 & 4.498 & 6.53 & -45.13 & 0.818 \\
5 & 6.187 & 7.23 & -16.87 & 11.336 \\
\hline
\end{tabular}

In the model the tower is divided into four groups of elements (Figure 10). Within each group the material is modelled as homogeneous and isotropic. The mass density $\rho$ of group 1 and 4 elements is assumed to be equal to $1834 \mathrm{~kg} / \mathrm{m}^{3}$ (drawn from the literature), while for groups 2 and 3, the assumed values are $10 \%$ lower in order to account for the presence of conglomerate layer in the masonry walls revealed by endoscopies. The initial values adopted for the material's elastic moduli, $E=2.45 \mathrm{GPa}$ and $v=0.2$, equal for all groups, were drawn from previous studies [9]. The stiffness of the spring elements, $K_{c d}=$ $4.37510^{7} \mathrm{~N} / \mathrm{m}$, was chosen in according to analogous studies [4].

The FE model developed shows non-negligible differences in eigenfrequencies with respect to experimental results, rather slight for the first three modes, and more accentuated for the last two (see Table 4). Analogously, 
the first three mode shapes of the FE model appear similar to the experimental ones, while the two others present more pronounced differences (see MAC values in Table 4). Thus, it was decided to use only the first three modes to update the FE model, as they are, in any event, able to characterize the dynamic behaviour of the whole structure.

The process of Model Updating was performed following the Trust Region Gauss-Newton Method [12] and optimizing the differences between experimental and numerical eigenfrequencies and mode shape components and choosing the elastic moduli of the four groups of elements as tuning parameters.

Updating leads to a set of parameters values very different from the initial ones (Table 5). After the optimization process, the FE model exhibits good agreement with the experimental results, both in terms of eigenfrequencies and mode shapes (Table 6). The close approximation achieved by the updated model can be immediately appreciated by noting the very small frequency percentage error, even though the mode shapes do present some small discrepancies.

Table 5: $\quad$ Initial and updated values of elastic moduli.

\begin{tabular}{ccc} 
& $\begin{array}{c}\text { Initial value } \\
{[\mathrm{GPa}]}\end{array}$ & $\begin{array}{c}\text { Updated value } \\
{[\mathrm{GPa}]}\end{array}$ \\
\hline$E_{1}$ & 2.450 & 3.296 \\
$E_{2}$ & 2.450 & 1.610 \\
$E_{3}$ & 2.450 & 0.631 \\
$E_{4}$ & 2.450 & 0.631 \\
\hline
\end{tabular}

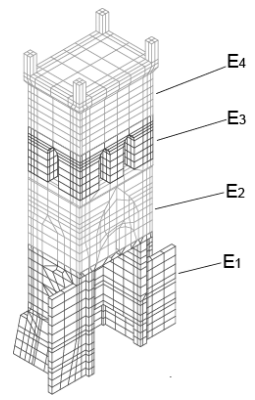

Table 6: $\quad$ Experimental, FE initial and FE updated modal data.

\begin{tabular}{cccccc}
\hline Mode & $f_{\text {EXP }}[\mathrm{Hz}]$ & \multicolumn{3}{c}{$f_{\text {ADINA }}[\mathrm{Hz}]$} & MAC [\%] \\
& & Initial & Updated & $\Delta \mathrm{f}[\%]$ & \\
\hline 1 & 1.28 & 1.3266 & 1.2785 & $0.12 \%$ & 75.71 \\
2 & 1.82 & 1.9565 & 1.7980 & $1.21 \%$ & 97.99 \\
3 & 3.03 & 3.4798 & 3.0352 & $-0.17 \%$ & 77.57 \\
\hline
\end{tabular}

\section{Some comparisons and conclusions}

The marked heterogeneity of the masonry clearly emerges from the experimental programme carried out on the Tower of Matilde. The large differences between the values of the mechanical properties obtained from (local) static tests and (global) dynamic ones suggest that the combined use of static and dynamic tests is anything but a simple matter. In fact, static tests deal with the local values of the mechanical properties, while dynamic tests, on the other hand, are concerned 
with the global mechanical behaviour of the structure. Thus, determining the actual stiffness of each different part of the tower turned out to be a complicated task, affected by a non-negligible level of indeterminacy.

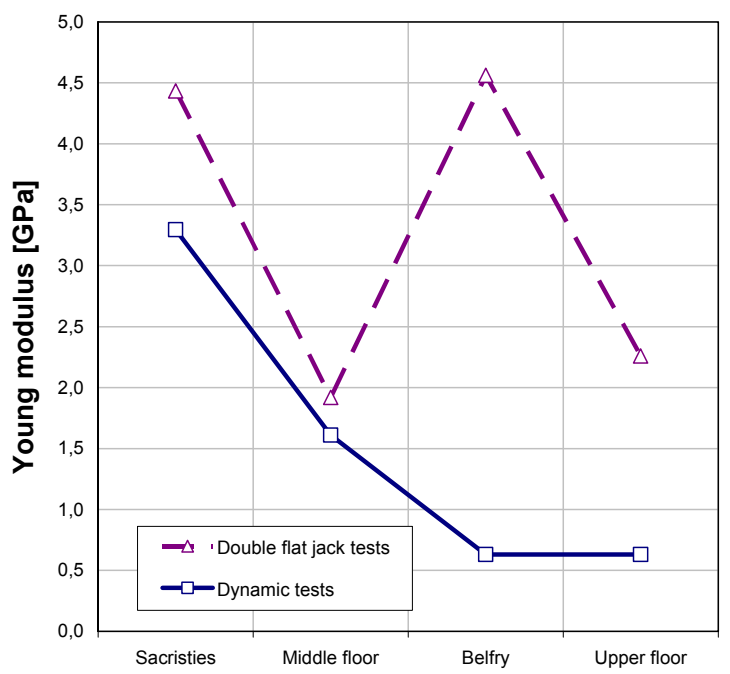

Figure 11: Comparison between tangent elastic moduli evaluated via static and dynamic tests.

However, a certain agreement can be observed between the values of the tangent Young's modulus estimated from double flat jack tests and those deduced from the model updating process (Figure 11): the two diagrams are quite close in correspondence to the lower part of the tower, though they differ greatly in correspondence to its upper part. Such a result seems to be consistent with the FE optimization procedure used to update the model, in which the real (cracked) masonry of the tower has been schematised as an equivalent, uncracked continuum by properly tuning the values of Young's modulus. The masonry walls in the upper part of the tower show widespread cracking, while the lower part appears to be in quite good condition. Thus, it seems reasonable that the equivalent elastic modulus (used in the FE analysis) for the upper part of the tower turned out to be considerably lower than the experimental one, evaluated on an undamaged portion of masonry. Such differences may be further explained by considering, firstly, that the Young's moduli estimated by the FE model are affected by a certain approximation depending on the subdivision introduced. Secondly, it should be kept in mind that viscoelastic, long-term redistribution of the internal stresses between the different layers composing each wall should not be excluded. Finally, all findings suggest that great care should be used in pushing the analysis too far into the details. Furthermore, a predominantly comparative use of the experimental results stemming from the combined application of different study techniques actually seems the most profitable. 


\section{References}

[1] Binda, L., Saisi, A., Tiraboschi, C., 2000. Investigation procedures for the diagnosis of historic masonries. Construction and Building Materials, vol. 14, pp. 199-233.

[2] Modena, C., Valluzzi, M.R., Tongini Folli, R., Binda, L., 2002. Design choices and intervention techniques for repairing and strengthening of the Monza cathedral bell-tower. Construction and Building Materials, vol. 16, pp. 385-395.

[3] De Sortis, A., Antonacci, E., Vestroni, F., 2005. Dynamic identification of a masonry building using forced vibration tests. Engineering Structures, vol. 27, 155-165.

[4] Gentile, C., Saisi, A., 2004. Dynamic-based F.E. model updating to evaluate damage in masonry towers. Proceedings of IV SACH Structural Analysis of Historical Construction, Padova, Italy.

[5] Cakmak, A.S., Moropoulou, A., Mullen, C.L., 1995. Interdisciplinary study of dynamic behaviour and earthquake response of Hagia Sophia. Soil Dynamics and Earthquake Engineering, vol. 14 , pp. 125-133.

[6] Lotti, D., 1980. San Miniato: vita di un'antica città. SAGEP, Genova. (in Italian)

[7] Cristiani Testi, M.L., 1967. San Miniato al Tedesco: saggio di storia urbanistica e architettonica. Marchi \& Bertolli, Firenze. (in Italian)

[8] Bennati, S., Nardini, L., Salvatore, W., 2005. Dynamical behaviour of a masonry medieval tower subjected to bell's action. Part I: bell's action measurement and modelling. ASCE Journal of Structural Engineering, vol. 131, No.11.

[9] Bennati, S., Nardini, L., Salvatore, W., 2005. Dynamical Behaviour of a Masonry Medieval Tower subjected to Bell's Action. Part 2: Measurement and Modelling of the Tower Motion. ASCE Journal of Structural Engineering, vol. 131, No.11.

[10] Bennati, S, Della Maggiora, M, Salvatore, W., 2003. On the Collapse of a Masonry Tower subjected to Earthquake Loadings. Proceedings of ERES 2003, the Fourth International Conference on Earthquake Resistant Engineering Structures, September 2003, Ancona, Italy.

[11] Bennati, S, Nardini, L, Salvatore, W., 2004. Comportamento dinamico e al collasso di un campanile medievale in muratura soggetto ad azioni sismiche. Atti del XI Convegno Nazionale ANIDIS “L’Ingegneria Sismica in Italia", Genova. (in Italian)

[12] Nardini, L., 2005. Structural identification and model updating for damage detection in civil constructions. Ph.D. Thesis, Department of Structural Engineering, University of Pisa. 